\title{
Sonido sabanero y sonido paisa. La producción de música tropical en Medellín durante los años sesenta
}

\author{
Juan Sebastián Ochoa \\ Bogotá. Pontificia Universidad Javeriana \\ 2018. $388 \mathrm{p}$. \\ Juana Catalina Chaves Castaño \\ Antropóloga. Magister (c) en Antropología. Profesora del Departamento \\ de Antropología y Sociología de la Universidad de Caldas. \\ $\checkmark$ juana.chaves@ucaldas.edu.co \\ (1D) ORCID: 0000-0002-3616-511X \\ $\checkmark$ Google Scholar
}

Leer un texto, cualquiera sea su naturaleza, puede asimilarse con un ejercicio antropológico sobre todo por la posibilidad de explorar formas otras de ver, contar y (d)escribir realidades. El libro se convierte en una evidencia material, en el sentido arqueológico, a la que accedemos por decisión o por azar y, dado que el autor no puede revelar a viva voz todo lo que entraña su obra, deja la puerta abierta a las interpretaciones y elucubraciones que los demás hacen de ella. Sobre esta premisa, la siguiente reseña presenta el Sonido sabanero y sonido paisa. La producción de música tropical en Medellín durante los años sesenta, desde una perspectiva particular que, aunque espera dar cuenta de todos los elementos relevantes, al final pondera aquellos que fueron de especial interés más por mis propias subjetividades que por la innegable riqueza de la obra.

Para empezar, es importante decir que Juan Sebastián Ochoa es Maestro en Música y Magister en Estudios Culturales, trayectoria académica que ha dedicado a estudiar los sonidos tradicionales y populares de la música colombiana. Así, la obra que aquí se reseña, es el resultado de su tesis doctoral en Ciencias Sociales y Humanas que parte del interés sobre la relación entre lo tradicional y lo masivo en la 
música tropical en Medellín en los años sesenta, y cómo esta relación puede aportar elementos para comprender los procesos de modernidadmodernización en Colombia a mediados del siglo XX con la llegada de los medios masivos de comunicación, cuestión que transversaliza los cinco apartados que componen el texto.

El primer capítulo presenta la construcción teórica del objeto de estudio que, desde un enfoque interdisciplinar, conjuga perspectivas históricas, sociológicas, musicológicas y de los estudios de la comunicación, alrededor de tres conceptos principales: lo tradicional, lo masivo y lo popular. Para ello, el autor realiza un recorrido por los antecedentes conceptuales que inician con los popular music studies, enfoque sociológico anglosajón de los años 80's que retoma parte de los estudios sobre industrias culturales de Theodor Adorno y Max Horkheimer; luego se centra en las reflexiones de los Estudios Culturales, particularmente las de Jesús Martín Barbero, Néstor García Canclini y Joaquín Brunner y finaliza con algunas consideraciones de los modelos conceptuales de Mijaíl Bajtin, Pierre Bourdieu y Howard Becker.

A partir de este diálogo teórico, Ochoa define las músicas populares-tradicionales como "aquellas músicas, sean rurales o urbanas, que presentan poco o ningún proceso de masificación mediatizada [en oposición a la músicas populares-masivas que son aquellas], que circulan ampliamente por los medios de comunicación y las industrias culturales" (p. 40). No obstante, el proceso de masificación que analiza el autor, no se reduce al papel de los medios de comunicación masivos, sino que amplía la perspectiva a las interacciones de los distintos actores que intervienen en la producción de las músicas populares-masivas; dichas interacciones son asumidas como mediaciones (en el sentido martín-barberiano) en donde la música se entiende "como un acto comunicativo complejo que construye cultura" (p. 48). Este concepto, a su vez, le permite reelaborar la idea de producción que tradicionalmente se ha asumido como un proceso artístico para crear un producto musical y enfocarla en

la forma en que, a través del tiempo y enmarcado en unas condiciones históricas, sociales y económicas particulares, un cierto tipo de músicas se van gestando y tomando una fuerza específica [es decir], comprender esta producción como proceso nos lleva a un análisis tanto de los repertorios como de la sociedad en la que estos se forjan. (p. 56) 
Esta última idea va de la mano con una intencionalidad clara del autor y es demostrar cómo las configuraciones de poder que se dieron en las interacciones entre compositores, intérpretes, dueños de disqueras y programadores de radio, entre otros actores, intervinieron en la producción de música tropical en Medellín durante los años sesenta.

El segundo capítulo, está construido a partir de una aproximación diacrónica al sonido sabanero, que se enfoca en las trayectorias biográficas y artísticas de los músicos y la emergencia histórica y musicológica de estos repertorios tropicales; en ese sentido, el sonido sabanero hace referencia a las músicas de acordeón, de bandas de viento y a las orquestas tipo big band que surgen en la región Caribe, específicamente en los Departamentos de Atlántico, Bolívar, Córdoba y Sucre en la década de 1940, a través de un fuerte proceso de masificación, no obstante, se diferencian del sonido vallenato que, a pesar de también estar asociado a las músicas tropicales de la costa, tiene adscripciones culturales y geográficas más cercanas al Magdalena Grande (La Guajira, Magdalena y Cesar). Nombres como Lucho Bermúdez, Pacho Galán, Clímaco Sarmiento, Simón Mendoza, Rufo Garrido, Trío Matamoros, Noel Petro, La sonora Cordobesa, Pedro Laza y sus Pelayeros, Lisandro Meza, Aníbal Velásquez, Calixto Ochoa, Alfredo Gutiérrez, Los corraleros de Majagual, los Caporales del Magdalena, entre otros, representan, en sus distintos formatos musicales y temporalidades, el sonido sabanero propuesto por Ochoa.

Siguiendo el enfoque diacrónico, el autor realiza un análisis de cómo el sonido sabanero y los músicos que lo personifican, son producto de la hibridación de dinámicas regionales-locales de creación artística e influencias musicales del Gran Caribe que llegaron al país entre los años 1920 y 1940 a través de la radio, el cine y los gramófonos generando nuevas sonoridades que compaginaron lo moderno y lo tradicional. Sin embargo, los formatos de las agrupaciones generaron una distinción entre las músicas populares-masivas y las músicas populares-tradicionales, en donde las primeras, tipo Lucho Bermúdez y Pacho galán, se asociaban más a las élites y los espacios festivos como clubes y salones y las segundas se asimilaban con lo rural y las clases bajas, así

mientras las músicas populares-masivas, funcionaban como un marcador de modernización cultural, las músicas popularestradicionales podían ser vistas como manifestaciones de atraso o expresiones de las capas "menos educadas", es decir, las prácticas y consumos musicales también están marcados por una distinción de clase. (p. 80) 
Por otra parte, el proceso de masificación también es analizado por el autor como la conjugación de los intereses de las disqueras, preferencias de los músicos, influencia de los directores artísticos y estrategias de marketing que dieron como resultado la inclinación por grabar repertorios locales (porros, cumbias y mapalés) en versiones estilizadas de orquestas de salón, que más allá de tener un espíritu folclorista o una agenda política de rescate de las músicas tradicionales, obedece a las necesidades de proveer nuevas sonoridades y cautivar nuevos públicos. En ese sentido, destaca, por ejemplo, la labor de Discos Fuentes a la cabeza de su dueño y fundador Antonio Fuentes, como muestra de "cómo las apuestas de individuos particulares, ya sea por intuiciones mercantiles o por deseos o motivaciones personales, también resultan relevantes en la orientación de las producciones musicales como el fruto de procesos históricos" (p. 104).

Otro elemento importante en este capítulo es la relación que establece entre los espacios de interpretación y las características de los músicos y la instrumentación. Los músicos que se dedican a grabar en estudios o a tocar en clubes, van adquiriendo unas convenciones de su profesión asociadas con la elegancia, la élite, lo urbano y lo moderno, lo cual se reflejaba en lo instrumental al incorporar saxofones, contrabajo, batería, maracas y congas e interpretar un repertorio escrito denotando cierta "inmovilidad", contrario a lo que ocurre con los músicos del formato callejero que pueden tocar mientras caminan precisamente por la condición transportable de sus instrumentos y que también genera gran capacidad de improvisación, no obstante, se asociaban con espacios rurales, al aire libre y fiestas populares de las clases bajas. Al respecto, el autor concluye que

la relación entre las músicas populares-tradicionales y las popularesmasivas las condiciones técnicas y tecnológicas de producción ocupan también un factor relevante: no es lo mismo hacer música en el solar de una casa, en una corraleja o recorriendo un pueblo, que hacerlo en una caseta o en un estudio de grabación. Estos cambios en los espacios y recursos condicionan también la forma de producir la música y consumirla, de tal manera que los cambios en las sonoridades y formatos no se dan únicamente por decisiones estéticas, sino, además y en gran medida, por soluciones prácticas. (p. 156)

Soluciones prácticas que van a tener lugar en la posterior adaptación del sonido sabanero "callejero" al sonido sabanero de estudio. Finalmente, este capítulo analiza las transformaciones en los ritmos asociada a ese proceso masificador evidente en la proliferación de nuevas sonoridades que, "en muchas ocasiones, se trataban más de la invención 
de un nombre nuevo que de la creación de una estructura rítmica o melódica nueva" (p. 174). Así, tenemos un amplio repertorio de porros, cumbias, gaitas, jalaítos, paseaítos, tumbasónes, chiquichás, paseboles, merecumbés, guarachas, entre otros, que también se caracterizaron por un cambio en el tempo que refleja, por un lado, la aceleración de los tiempos modernos y por otro, las preferencias del público por músicas alegres y festivas asociadas más a un ambiente de carnaval que a una identidad étnica regional. Con todo lo anterior, Ochoa es enfático en entender la evolución del sonido sabanero no como un proceso unilineal, ni unidireccional que parte de músicas rurales "puras" sino a partir de un modelo interaccionista en el que confluyen múltiples relaciones de influencias sonoras, gustos, prácticas musicales locales, procesos de masificación, circulación y consumo musical.

Siguiente la estrategia diacrónica, el tercer capítulo se dedica principalmente a caracterizar el sonido paisa como una relectura por parte de agrupaciones de la ciudad de Medellín, conformadas por adolescentes y jóvenes de las clases altas y media altas a mediados de los años cincuenta y principios de los sesenta, del sonido sabanero que se había popularizado a través de los medios masivos de comunicación. Nombres como Los Teen Agers, Los Golden Boys, Los Claves, Los Falcons, Los Black Stars, Los Hispanos y Los Graduados son representativos de esta nueva sonoridad.

El autor describe cómo en un contexto de auge industrial y económico de la ciudad de Medellín en los años cincuenta, se radicaron allí las disqueras más importantes del país (Discos Fuentes, Sonolux, Codiscos, entre otras) y algunos de los músicos del sonido sabanero como Lucho Bermúdez, Los Corraleros de Majagual, Lizandro Mesa y Alfredo Gutiérrez. Esto generó un consumo del sonido sabanero a través de las bandas tipo jazz band en los clubes de la ciudad y de los conjuntos tradicionales a través de la radio y las grabaciones de estudio. Sin embargo, el formato de orquesta comenzó a considerarse acartonado y poco llamativo para las nuevas generaciones y las agrupaciones tradicionales no correspondían con la noción de élite de los clubes. Paralelamente, iban surgiendo agrupaciones de jóvenes músicos aficionados que acompañaban fiestas de casa y que de forma espontánea comenzaron a ser invitados a tocar en clubes, grilles y casetas, apuntando a una distinción generacional modernizante reflejada en los nombres en ingles que adoptaron, el uso de instrumentos eléctricos asociados al rock and roll, una estética que emulaba los adolescentes estadounidenses y un estilo alegre y desparpajado para interpretar la música que, en un principio, estaba conformada por sonidos eclécticos 
que iban desde música italiana, baladas, twist, hasta la música tropical del caribe. Este estilo generó una amplia demanda de los públicos jóvenes, convirtiéndose en un producto sonoro y visual atractivo para las disqueras y los productores musicales que fueron homogenizando y estandarizando estas sonoridades eclécticas para consolidar lo que se conoce como sonido paisa.

En este proceso se pasó de un eclecticismo, a finales de la década de los cincuenta y comienzo de los sesenta, a una creciente homogenización sonora a finales de la década, de tal manera que, para los años 1968, 1989 o 1970, no resultaba del todo fácil para el público distinguir un conjunto del otro. (p. 233)

Ahora, bien en términos de esa sonoridad, Ochoa identifica tres elementos importantes, los instrumentos, las armonías y el ritmo, que, a diferencia del sonido sabanero, obedecen a procesos espontáneos producto de la poca experticia y profesionalización de los músicos del sonido sabanero. Así, por ejemplo, la inclusión del bajo eléctrico no tenía una intencionalidad identitaria ni estética sino un objetivo práctico relacionado con la posibilidad de amplificar el sonido. "El bajo punzante de sonido paisa no es la expresión de ciertos sentimientos y emociones preexistentes, sino que surgió de manera azarosa y, luego, a partir de este, se generaron ideas e identificaciones que después se conceptualizaron" (p. 242). Igualmente, la guitarra eléctrica tuvo un enfoque más simbólico que musical, pues al estar asociada al rock, aunque las mismas interpretaciones del sonido sabanero dejaran de lado las técnicas y convenciones de este género, daban una imagen juvenil y modernizante.

El uso del bajo eléctrico, la guitarra eléctrica y el solovox les proporcionaba a los conjuntos paisas una distinción reconocible, lo cual los diferenciaba de los conjuntos sabaneros, pero el mayor aporte se daba en la imagen, asociada a los grupos de rock and roll norteamericanos de la época. (p. 248)

Con respecto al análisis que hace de las armonías y los ritmos, cobra sentido el argumento que transversaliza el texto sobre cómo para abordar las músicas populares-tradicionales y las músicas populares-masivas es preciso partir de la comprensión de las trayectorias biográficas de los músicos y, para el caso específico, los músicos del sonido sabanero y los músicos del sonido paisa, entre los cuales hay una evidente diferencia asociada precisamente a las trayectorias y los contextos en los que se movían. 
Como los integrantes de los conjuntos antioqueños no eran en su mayoría músicos de profesión y tampoco eran destacados intérpretes de instrumentos, el acople rítmico de los conjuntos -es decir, la exactitud con la que los diferentes músicos interpretan cada una de las notas en el momento preciso- no era la mejor. Y esta sí es una diferencia clara y generalizada con respecto a los músicos del Caribe colombiano, quienes en términos generales si tienen un sentido rítmico altamente desarrollado. (pp. 253-254)

Esta falta de destreza y conocimiento generó que el sonido paisa se viera como una degradación del sonido sabanero y fuera denominado de manera peyorativa como chucu chucu, sin embargo, Ochoa se distancia de estas apreciaciones pues considera que el sonido paisa tiene un valor en sí mismo al representar, por un lado, la idea de modernización que tenía la sociedad de Medellín a través de la fetichización de elementos visuales de cómo se ve lo moderno y por otro, el blanqueamiento musical de la música tropical que tenía una connotación étnica y social marginal y que al ser interpretada por músicos blancos de las clases altas y media altas de la ciudad daban la licencia de bailar música alegre y desparpajada sin que ello fuera vulgar.

A nivel metodológico, el autor nos plantea conjugar tres aproximaciones: la diacrónica, evidenciada en los capítulos 2 y 3, la sincrónica y el análisis de la matriz cultural predominante. La perspectiva sincrónica, por su parte, le es útil para analizar el fenómeno en una escala temporal y espacial específica como los es la Medellín de los años sesenta en un contexto de interacción y entramados sociales amplios de músicos, compositores, arreglistas, directores artísticos, disqueras, comentaristas radiales, almacenes de discos, nuevas tecnologías y públicos y que hace parte del cuarto capítulo de la obra. Así, partiendo de la noción de mundo del arte de Howard Becker, caracteriza el aporte de cada uno de estos actores a la masificación de los sonidos sabanero y paisa concluyendo que el auge que tuvieron estas músicas se debe, por un lado, a procesos individuales de personas que vieron estos nuevos ritmos como una posibilidad comercial, de entretenimiento o en el sentido contrario, como un retroceso cultural y por otro, al cubrimiento de un nicho de mercado que las llevó, desde escenarios populares, como las corralejas (para el caso del sonido sabanero) y las murgas (para el caso del sonido paisa), hasta los estudios de grabación, creando así una mediación simbólica entre lo rural y lo urbano, entre lo tradicional y lo modernizante.

Finalmente, para el quinto capítulo, la idea de matriz cultural es tomada de la obra de Martín-Barbero, siendo sugerente para analizar las 
músicas populares-masivas como "moldes creativos y expresivos [en una constante interacción y articulación], que se adaptan y reaparecen en diferentes momentos y contextos" (p. 29). Ochoa plantea que la matriz molde que originó la música tropical de los años sesenta en Colombia se puede explicar a través de la noción de espíritu carnavalesco de Mijaíl Bajtín, en tanto las características musicales y visuales del sonido sabanero y el sonido paisa se asocian con unas actitudes y lógicas carnavalescas que se evidencian específicamente en las letras de las canciones y el performance de algunos de los músicos, por ejemplo, en las letras es común encontrar alusiones a la risa o la burla hacia sí mismos o lo otros, la banalización de lo sagrado, la contraposición de órdenes ("el mundo al revés"), las exageraciones y el doble sentido, mientras que en lo performático encontramos personajes carnavalescos como Alfredo Gutiérrez, Noel Petro y Gustavo "El Loko" Quintero, quienes son reconocidos por sus actitudes histriónicas en los escenarios. Sin embargo, aunque este espíritu carnavalesco desmarca al sonido sabanero y al sonido paisa de una pretensión de seriedad o trascendencia y los ponen más en el nivel de generadores de entretenimiento y modernización, el autor plantea un análisis interesante en la medida en que se cuestiona si este proceso de carnavalización corresponde a una estrategia para sobrellevar una realidad permeada por la violencia y al mismo tiempo una forma de desnaturalizar y desjerarquizar para configurar una indiferencia ante una cotidianidad marcada por el dolor.

Para concluir, Ochoa se aleja de la postura de autores como Wade en donde los sonidos sabanero y paisa son asumidos como un "freno" o retroceso en un modelo lineal de progreso de la música tradicional y se acerca más a la idea de entender que la modernidad "no se trata de 'avances' o 'retrocesos', sino de transformaciones culturales en las que los cambios en las condiciones de producción generan cambios en las producciones simbólicas" (p. 361). Así mismo, proyecta dos posibles líneas de investigación; una enfocada en la relación ritual que, desde una perspectiva antropológica, existe entre la música tropical y las fiestas decembrinas; la segunda, más amplia en escala, que plantea el análisis de las diferentes manifestaciones de culturas populares latinoamericanas desde la perspectiva del espíritu carnavalesco que desarrolló.

La obra de Ochoa es una contribución interesante en términos teóricos y metodológicos a los estudios de la cultura popular que, además de compaginar de una forma creativa y rigurosa (evidente en una amplia bibliografía de más de 250 títulos) la música tropical y los procesos de modernización en Colombia, plantea y desarrolla debates antropológicos y sociológicos profundos sobre la configuración de la identidad colombiana. Así, este trabajo se suma a los ya elaborados en el marco de la Colección de Culturas Musicales de Colombia de la cual Ochoa es arte y parte. 